\section{Cell-free Transmission of Mouse Neuroblastoma}

AFTER the description of the cell-free transmission of neuroblastoma $\mathbf{C 1 3 0 0}$, a transplantable tumour in strain $\mathrm{A} / \mathrm{J}$ mice, by Prasad et al. ${ }^{1}$, we made ten attempts to reproduce their results, first using their extraction procedure and then by using the viral concentration procedure of $\mathrm{Moloney}^{2}$, modified by Huebner et $a l^{3}$. We inoculated twenty-eight prenatal, fortyseven newborn, and sixteen 4-week-old $\mathrm{A} / \mathrm{J}$ mice but failed to obtain positive results, even after 100 days postinoculation. Because we used newborn mice that are usually more susceptible to oncogenic viruses than the older mice used by Prasad et al., and viral concentrates rather than filtrates, we expected to increase our chances of transmission.

We have found numerous intracisternal A-type particles and rare budding $\mathrm{C}$-type particles in $\mathrm{C} 1300$ tumours, confirming the results of Prasad et al. In addition, we have found specific antigens of C-type RNA tumour viruses by the complement fixation test. $\mathrm{A} / \mathrm{J}$ mice, like many other inbred and outbred strains of mice, are known to carry wild-type infectious C-type RNA viruses in spontaneous and transplanted non-leukaemic tumours, but except for the FBJ virus, no C-type RNA virus from solid tumours of any mouse strain has been shown to induce solid tumours of the original type.

DAVID D. MYERS

HANS MEIER

The Jackson Laboratory,

Bar Harbor, Maine 04609

ROBERT J. HUEBNER

Viral Carcinogenesis Branch, National Cancer Institute, Bethesda, Maryland 20014

\section{VERNON}

Microbiological Associates, Bethesda, Maryland 20014

\section{J. WALKER}

Flow Laboratories,

Rockville, Maryland 20850

${ }^{1}$ Prasad, K. N., Zambermard, Z., Lasher, R., and VanWaert, M. H., Nature, 228, 997 (1970).

2 Moloney, J. B., J. Nat. Cancer Inst., 24, 933 (1960)

3 Huebner, R. J., Hartley, J. W., Rowe, W. P., Lane, W. T., and Capps, W. I., Proc. US Nat. Acad. Sci., 56, 1164 (1966).

\section{Effects of Amphetamine on Single Cell Activity in a Catecholamine Nucleus, the Locus Coeruleus}

THE action of amphetamine on the central nervous system has been related to its ability to release and inhibit the re-uptake of dopamine (DA) and noradrenaline (NA) at presynaptic terminals $^{1-4}$. Abundant catecholamine (CA) stores have been demonstrated in the cells of the locus coeruleus ${ }^{5-7}$. These two observations suggest that amphetamine causes the release and decreased re-uptake of $\mathrm{CA}$ from locus coeruleus cells. The drug, by promoting the accumulation of CA postsynaptically, might thereby initiate neuronal feedback inhibition of locus coeruleus units; such a mechanism has been postulated to explain biochemical observations on CA systems treated with amphetamine ${ }^{8}$. The opposite effect, feedback stimulation, has also been postulated to explain observations of the CA blocking effects of neuroleptics (chlorpromazine and haloperidol $)^{9-11}$

To evaluate these hypotheses, extracellular microelectrode recordings were made from single neurones in the rat locus coeruleus, before and after treatment with amphetamine. Chlorpromazine was also given to evaluate its anti-amphetamine effects; such effects have been described previously in both clinical $^{12}$ and behavioural settings ${ }^{13-15}$.

We used male Charles River rats weighing 225-300 g. Recordings were made by techniques similar to those previously described ${ }^{16}$. Animals were anaesthetized with chloral hydrate (400 mg/kg, intraperitoneally) and mounted in a stereotaxic apparatus. Coordinates, representing the outer dimensions of the locus coeruleus, were estimated by direct measurement from serial pontine sections of the brain from a Charles River rat, sectioned along the axes of König and Klippel ${ }^{17}$. A $3 \mathrm{~mm}$ burr hole was made at coordinates within the range of lateral 1,000-1,300 $\mu \mathrm{m}$ and posterior $1,700-2,200 \mu \mathrm{m}$. Tungsten microelectrodes with tip diameters of $1 \mu \mathrm{m}$ were lowered through the burr hole by a hydraulic microdrive. Signals were passed through a high input-impedence amplifier and displayed on an oscilloscope. Unit rates were measured by an electronic counter whose analogue output was traced graphically by a potentiometric recorder. Signals from the oscilloscope $(700-2,000 \mathrm{~Hz})$ also drove an audio monitor.

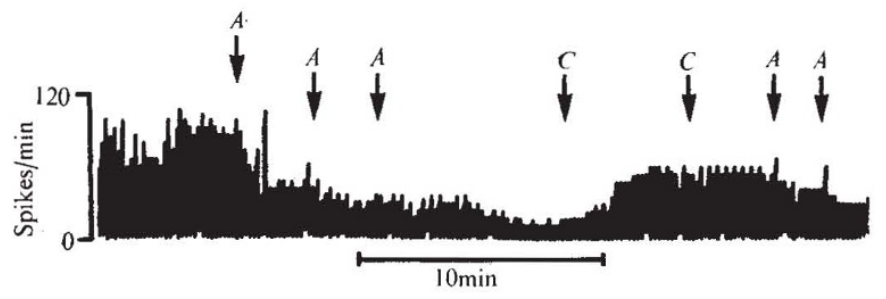

Fig. 1 Typical response of a locus coeruleus unit to amphetamine $(A)$ and chlorpromazine $(C)$. Spontaneous rate was 90 spikes/min. The record consists of the number of spikes counted over consecutive $10 \mathrm{~s}$ intervals. Within $30 \mathrm{~s}$ after the intravenous injection of amphetamine $(0.2 \mathrm{mg} / \mathrm{kg})$, a marked decrease in rate was observed. Two subsequent doses of amphetamine $(0.4,1.0)$ produced additional slowing (to 12 spikes $/ \mathrm{min}$ ). A recovery of rate to two thirds of the original was observed within $1 \mathrm{~min}$ after i.v. injection of chlorpromazine $(1.0 \mathrm{mg} / \mathrm{kg})$. Additional chlorpromazine (1.0) had no additional effect. Subsequent doses of amphetamine $(0.5,1.0)$ were less effective in decreasing the rate than in the untreated animal.

Only cells with a stable rate and a uniform spike amplitude were used. The waveform was observed for 5-10 min. Drugs were then administered intravenously to the tail in 0.05 $0.2 \mathrm{ml}$. volumes given slowly over a period of 5-10 s. $d$-Amphetamine sulphate and chlorpromazine hydrochloride were given dissolved in distilled water at concentrations of $0.25 \mathrm{mg} / \mathrm{ml}$. or $2.5 \mathrm{mg} / \mathrm{ml}$. Only one unit was studied in each rat to avoid possible residual drug effects. At the completion of an experiment, the location of the electrode was marked by making an anodal electrolytic lesion ( $5 \mu \mathrm{A}$ for $60 \mathrm{~s}$ ). Animals were perfused through the left ventricle of the heart with a solution of $5 \%$ glutaraldehyde in saline. Serial frozen sections were cut at $50 \mu \mathrm{m}$ and stained with cresyl violet. The location of each recording electrode was precisely identified in this manner. Fluorescent histochemical studies of the brain were carried out using the techniques described before ${ }^{5,18-20}$.

Recordings were made from single units in thirty-five rats; subsequent histological examination showed that ten of these were in the locus coeruleus, and in these spontaneous activity decreased to less than one third of the original rate after small intravenous doses of $d$-amphetamine (Fig. 1). A marked response to amphetamine occurred with doses as small as $0.2 \mathrm{mg} / \mathrm{kg}$. Larger doses produced further depression, the maximum depression of firing being achieved with 0.5 $1.5 \mathrm{mg} / \mathrm{kg}$ (Fig. 1). Although in each recording a single prominent unit spike was monitored, multiple "background" spikes from neighbouring locus coeruleus cells also showed a gross reduction in frequency with amphetamine. 